\title{
Forecasting Russia's Key Macroeconomic Indicators with the VAR-LASSO Model'
}

\author{
Nikita Fokin, Russian Presidential Academy of National Economy \\ and Public Administration \\ fokinikita@gmail.com \\ Andrey Polbin, Russian Presidential Academy of National Economy \\ and Public Administration; Gaidar Institute for Economic Policy \\ apolbin@iep.ru
}

This paper examines an application of the VAR-LASSO model to Russia's key macroeconomic indicators: GDP, household consumption, fixed asset investment, exports, imports, and the rouble real exchange rate, along with oil prices (as an exogenous variable). The slowdown in the Russian economy following the 2008-2009 crisis is modelled as a structural break in the unconditional mean of growth rates of the time series under examination. The model is estimated with the assumption of a common growth rate for GDP, consumption, investment, exports and imports (any discrepancies in actual growth rates are due to changing oil prices and other shocks), which provides a solid foundation for balanced medium-term forecasts using an econometric specification that factors in this constraint. The model exhibits fairly good predictive power when pseudo real-time forecasts are benchmarked against the forecast by the Ministry of Economic Development and the forecast given by the BVAR model in Pestova and Mamonov (2016b), as well as against the best (based on the BIC criterion) VAR(1) model and the classical ARIMA model. The estimated model is used to study functions for impulse responses to oil price shocks and to build scenario-driven forecasts for 2019-2024.

Keywords: vector autoregression; machine learning; regularised models; GDP forecast; Russian economy; curse of dimensionality; oil prices

JEL Codes: C53; C55; E21; E22; E27
Citation: Fokin, N. and Polbin, A. (2019). Forecasting Russia's Key Macroeconomic Indicators with the VAR-LASSO Model. Russian Journal of Money and Finance, 78(2), pp. 67-93.

doi: $10.31477 /$ rjmf.201902.67

\section{Introduction}

Forecasting macroeconomic indicators is the most important field in economic analysis. In-house forecasting models are employed by such regulators as the Bank

\footnotetext{
1 The authors would like to thank two anonymous reviewers for their helpful comments and remarks, which greatly improved the final version of the paper.
} 
of Russia, the Ministry of Economic Development (MED), and other ministries and agencies in charge of aspects of the economy and society, in order to make monetary and fiscal policy decisions. There are also a large number of research institutions in Russia that build their own forecasting models, including the Central Economic and Mathematical Institute of the Russian Academy of Sciences, the Institute of Economic Forecasting of the Russian Academy of Sciences, the Centre for Macroeconomic Analysis and Short-term Forecasting, the Higher School of Economics, the Gaidar Institute for Economic Policy, and the New Economic School (the RenCap-NES Leading GDP Indicator). However, economic forecasting in Russia exhibits some idiosyncrasies when compared with established global practice. Turuntseva (2011) explains that there is little transparency around the methodology behind almost all Russian forecasting models. We are generally allowed to see only the results and some statistical estimators that assess the quality of the forecasts produced by the models. Turuntseva also points out that, even if a model is described in detail, questions might still arise as to its specification, making it hard to judge how good or bad a forecast is. The following forecasting models are used in Russian literature: ARIMA models (Turuntseva et al., 2018), VAR models (Skrobotov and Turuntseva, 2015), large-scale macroeconometric models (Mikhailenko, 2005; Drobyshevsky et al., 2005; Uzyakov et al., 2009; Ayvazyan et al., 2013), factor models (Styrin and Potapova, 2009; Astafieva and Turuntseva, 2014; Porshakov et al., 2016), BVAR models (Demeshev and Malakhovskaya, 2015; Deryugina and Ponomarenko, 2015; Pestova and Mamonov, 2016b), DSGE models (Ivashchenko, 2013; Malakhovskaya, 2016; Kreptsev and Seleznev, 2016), and MIDAS models (Mikosch and Solanko, 2019).

In their review paper, Pestova and Mamonov (2016a) document the evolution of macroeconomic forecasting models in detail, from the very beginning (ARIMA models) to fairly advanced contemporary methods (DSGE, BVAR), and divide the models for the Russian economy into several classes: compliant vs. non-compliant with contemporary economic theory, and susceptible vs. non-susceptible to the curse of dimensionality. The curse of dimensionality refers to a situation where the number of variables in the equation to be estimated is close to or exceeds the number of observations. Since time series related to the Russian economy are quite short, ${ }^{2}$ the curse of dimensionality in forecasting is a relevant issue. Pestova and Mamonov outline a number of methods for avoiding it. First, they suggest using dynamic factor models in which variables are split into two groups: first, the main set of variables and factors that are usually identified on the basis of principal component analysis (PCA). The second option is Bayesian vector autoregression (BVAR), which, given certain types of prior distribution, allows a VAR model

\footnotetext{
${ }^{2}$ For instance, the US can use GDP time series from as early as 1947 (https://fred.stlouisfed.org/ series/GDPC1), while Russia can employ similar data only from 1995 (http://www.gks.ru/free_doc/ new_site/vvp/kv/tab6.htm).
} 
to be estimated in cases where the number of variables exceeds the number of observations. Pestova and Mamonov also mention certain hybrid approaches, in particular factor-augmented VAR models (FAVAR) and models with timevarying parameters.

There is another fundamental class of models employed to avoid the curse of dimensionality called VAR-LASSO models or, as a more general class, models with regularisation. This category is not mentioned by Pestova and Mamonov (2016a) and has generally received limited attention in domestic macroeconomic modelling. ${ }^{3}$ However, VAR-LASSO models enable effective selection from a large set of potential explanatory variables of the most relevant regressors for minimising forecasting errors without complex sampling methods, and could a priori prove of significant practical value in forecasting Russian macroeconomic indicators.

In the classical approach, when there are a large number of regressors, parameter selection in a VAR model based on an information criterion may require an extremely large number of possible regressor screening options to be estimated and benchmarked: with $n$ potential regressors there will be $2^{n}$ options for one equation.

Regularisation is a fairly simple exercise from the computational point of view: it seeks to minimise the error in the model's data approximation by penalising absolute values of the coefficients and effectively shrinking insignificant coefficients towards zero at each step. One possible application of the LASSO technique is to select relevant regressors, with subsequent estimation of the regressors coefficients using the classical ordinary least squares method (OLS post-LASSO), which allows less biased confidence intervals (compared with LASSO) for the indicators in question (Belloni and Chernozhukov, 2013).

This paper seeks to put the VAR-LASSO technique to the test for the forecasting and structural analysis of Russian macroeconomic indicators. The model the paper presents includes the following novel elements: first, its specification seeks to factor in the recent slowdown of the Russian economy, which is added as a structural break in the parameter vector of the unconditional growth rate around the 2008-2009 crisis. Second, the model takes into account the domestic economy's dependence on oil prices, which are added as an exogenous variable. Third, the model includes the assumed constraint that long-run growth rates in GDP, consumption, investment, exports, and imports are equal. The actual growth rates of the variables may differ due to oil price changes or domestic shocks. In introducing the constraint, we rely on a paper by Villani (2009), who employs a BVAR model to demonstrate the importance of background information on long-run growth in building forecasts. VAR models without constraints on the vector of constants may produce absurd long-run forecasts that do not maintain a macroeconomic balance. Fourth, nonzero lag coefficients are selected with LASSO.

\footnotetext{
${ }^{3}$ LASSO-style regularisation methods are employed by Baybuza (2018) to forecast inflation in Russia.
} 
The paper is organised as follows. Section 2 details the methodology behind models with regularisation and provides a specification and data description for the current model. Section 3 presents the results of the econometric estimation. Section 4 examines the model's predictive power. First, we build pseudo out-ofsample forecasts for 2015 and 2016 and benchmark them against de-facto values as well as the Ministry of Economic Development of the Russian Federation (MED) forecasts and BVAR-based forecasts generated by Pestova and Mamonov (2016b) in comparable experiments. Second, we run a number of classic tests to conduct formal statistical benchmarking in terms of forecasting accuracy with VAR(1) and ARIMA models. Third, we build a 2019-2024 forecast given several oil price scenarios, comparing our forecasts with forecasts by the MED, the International Monetary Fund (IMF), and the World Bank (WB). The conclusion outlines our key outcomes and findings.

The results demonstrate that long-run growth in macroeconomic indicators, adjusted for the effects of oil prices, stood at a quarterly level of $1.61 \%$ before the 2008 crisis and slowed to a quarterly level of $0.42 \%$ following the crisis. The oil price elasticity of GDP is 0.09 , with 0.13 for consumption, 0.21 for investment, 0.4 for imports, and 0.12 for the real exchange rate. The effect of oil prices on exports in constant prices is positive in the short run but turns statistically insignificant in the long run. When compared with the MED forecast and Pestova and Mamonov's BVAR forecasts, our model worked better for one of the scenarios. In terms of RMSE values, the VAR-LASSO model proved more accurate in forecasting GDP, consumption, and investment across several forecast horizons compared with the VAR(1) model, and better than the ARIMA model across all forecast horizons. The ARIMA model does a better job at forecasting exports and the real exchange rate, while import forecast outcomes are ambiguous and depend on the forecast horizon. Tests for the equal means of the forecast errors reveal that, in terms of statistical significance, consumption forecasts under the VAR-LASSO model are better than VAR(1)-based forecasts in one of the tests and better than ARIMA-based forecasts in all the tests. The results for investment are similar. The GDP forecast under the VAR-LASSO model is not significantly different from the VAR(1)-based forecast, which might be due to the low capacity of the tests given the small size of the samples. Nevertheless, the GDP forecast under VAR-LASSO is better in statistical significance terms than the ARIMA-based forecast at a level of $10 \%$.

\section{The regularisation, datasets, and model design}

\subsection{The regularisation in regressions: univariate and multivariate cases}

The LASSO regression as proposed by Tibshirani (1996) builds on Breiman's algorithm (Brieman, 1995) and adds a penalty to the least squares minimisation 
problem in the form of the $L_{1}$ norm of the model's coefficient vector indexed by the multiplicative factor $\lambda$ with a positive value (a penalty or tuning parameter), i.e.:

$$
Q(\beta)=\left(y_{t}-\beta_{0}-X_{t} \beta\right)^{\prime}\left(y_{t}-\beta_{0}-X_{t} \beta\right)+\lambda|| \beta||_{1} \rightarrow \min _{\beta},
$$

where $y_{t}$ is the dependent variable, $X_{t}$ is a set of regressors (explanatory variables), $\beta_{0}$ is the model constant, and $\beta$ is the coefficient vector of the regressors.

This provides a new solution to the minimisation problem for a certain set of coefficient vectors $\beta$ with penalties for model coefficients in the case of extreme absolute values. The constant is not part of the set of coefficients that are penalised. Parameter $\lambda$ can be selected with the help of the information criterion or crossvalidation. Cross-validation allows a set of coefficients to be selected that will provide the most accurate forecast, unlike the information criterion, which only minimises the in-sample variance of a forecasting error adjusted by the number of parameters. From the theoretical point of view, cross-validation is a more substantiated approach to selecting penalising parameters for forecasting purposes. In the case of time series, sliding window or LOO (leave one out) cross-validation can be used in view of the rigid ordering of data and impossibility of blending, contrary to the case of cross-sectional regressions. In this paper, we employ sliding window cross-validation.

Sliding window cross-validation implies a certain fixed forecast horizon for testing sample $h$. Subsequently, we use the training sample to estimate the model, building a forecast for $h$ upcoming periods and calculating a metric of the forecasting error, e.g. RMSFE (root mean squared forecast error), for all possible values of parameter $\lambda$. We then repeat the procedure until we have fed the last available observation from the testing sample.

Standardisation of variables is an important procedure in estimating the LASSO regression. Since we penalise all the coefficients for their absolute values equally (by one and the same parameter $\lambda$ ), the penalty will depend on the variables' variance (Song and Bickel, 2011; Gefang, 2014; Nicholson et al., 2017).

Hsu et al. (2008) produced one of the pioneering papers on the topic of LASSO-assisted parameter selection for a VAR model. The authors benchmark LASSO against the classical approaches to parameter selection employed by VAR models, against the Akaike Information Criterion (AIC), and against the Schwarz Information Criterion (SIC) to conclude that VAR-LASSO is preferable to the mentioned information criteria in terms of both its forecasting capability and its computational costs. The VAR-LASSO model has also been discussed in subsequent papers by Song and Bickel (2011), Li and Chen (2014), Davis et al. (2016), and Nicholson et al. (2017). The latter provides a classification of approaches to estimating VAR-LASSO and a software package for the programming language R, which enables the model to be estimated with different penalty options for overparameterisation and cross-validation and quality tests of pseudo out-of-sample 
forecasts. The use of VAR-LASSO for a large set of Russian time series (45 series with monthly frequency) is explored by Fokin (2019).

The VAR model for $t=1 \ldots T$ observations, with $k$ endogenous variables and $m$ exogenous variables, can be presented as follows:

$$
y_{t}=v+\sum_{l=1}^{p} \Phi^{(l)} y_{t-l}+\sum_{j=0}^{s} \beta^{(j)} x_{t-j}+u_{t}
$$

where $y_{t}$ is the vector of endogenous variables, $v$ is the vector of the constants, $\Phi^{(l)}$ is the coefficient matrix for $l$-th lags of endogenous variables, $x_{t}$ is the vector of exogenous variables, $\beta^{(j)}$ is the coefficient matrix for $j$-th lags of exogenous variables, and $u_{t}$ is i.i.d. $k$-dimensional white noise with zero expectation vector and a certain covariate matrix $\Sigma_{u}$. In general terms, the lag length for endogenous variables $p$ and exogenous variables $S$ may differ.

Minimisation for VAR-LASSO is as follows:

$$
\begin{aligned}
Q(v, \Phi, \beta)=\sum_{t=1}^{T}\left(y_{t}-v \sum_{l=1}^{p} \Phi^{(l)} y_{t-l}\right. & \left.-\sum_{j=0}^{s} \beta^{(j)} x_{t-j}\right)^{2} \\
& +\lambda\left(|| \Phi \|_{1}+|| \beta||_{1}\right) \rightarrow \min _{v, \Phi, \beta}
\end{aligned}
$$

It is similar to the univariate LASSO minimisation problem, but generalised for a multivariate model. Parameter $\lambda$ is equal for all equations. Nicholson et al. (2017) discuss other options for penalising the coefficients, e.g. specifications where diagonal coefficients of $\Phi^{(l)}$ matrices are penalised less than non-diagonal ones. In this case, the equation for variable $y_{1 t}$ is more likely to include lags for $y_{1 t}$ than for others; similarly, equation $y_{2 t}$ is more likely to include lags for $y_{2 t}$. There is also a specification that differentiates penalties for lags of different orders, as well as a number of other specifications. The present paper employs the classical LASSO penalty only.

\subsection{Data description}

The main objective of this paper is to build a model to forecast GDP and its main components: household consumption, investment in fixed capital, exports, and imports. On top of these parameters we use the real effective exchange rate as a measure of the competitiveness of the Russian economy, and oil prices as a key factor in the external economic environment. Table 1 provides a description of the data.

All the series are available quarterly from 1999Q1 to 2018Q4. In the case of real oil prices and the US CPI, we took monthly data and calculated average quarterly data to arrive at the real quarterly oil price. GDP, consumption, investment, export, and import series are presented in 2011 prices and are linked together from Rosstat's corresponding four series in 2003, 2008, 2011, and 2016 prices. 
Table 1. Model data

\begin{tabular}{|c|c|c|c|}
\hline Variable & Designation & Source & Note \\
\hline Real GDP & $g d p_{t}$ & Rosstat & Series seasonally adjusted with X-12 ARIMA \\
\hline Real household consumption & cons $_{t}$ & Rosstat & Series seasonally adjusted with X-12 ARIMA \\
\hline Real investment in fixed capital & $i n v_{t}$ & Rosstat & Series seasonally adjusted with X-12 ARIMA \\
\hline Real exports & $e x_{t}$ & Rosstat & Series seasonally adjusted with X-12 ARIMA \\
\hline Real imports & $i m_{t}$ & Rosstat & Series seasonally adjusted with X-12 ARIMA \\
\hline $\begin{array}{l}\text { Real effective rouble } \\
\text { exchange rate }\end{array}$ & reer $_{t}$ & $\begin{array}{l}\text { International } \\
\text { Monetary Fund }\end{array}$ & Raw data without seasonal adjustment \\
\hline $\begin{array}{l}\text { Real price of Brent } \\
\text { crude oil }\end{array}$ & poil $_{t}$ & $\begin{array}{l}\text { Federal Reserve } \\
\text { Bank of St. Louis }\end{array}$ & $\begin{array}{l}\text { Real oil prices calculated by deflating the } \\
\text { dollar-denominated nominal price for the } \\
\text { US seasonally adjusted CPI }\end{array}$ \\
\hline
\end{tabular}

\subsection{Model design}

Endogenous variables are as follows:

$$
\begin{gathered}
\mathrm{Y}_{\mathrm{t}}=\left[\Delta \log \left(g d p_{t}\right), \Delta \log \left(\text { cons }_{t}\right), \Delta \log \left(\text { inv }_{t}\right), \Delta \log \left(\text { ex }_{t}\right),\right. \\
\left.\Delta \log \left(\text { im }_{t}\right), \Delta \log \left(\text { reer }_{t}\right)\right],
\end{gathered}
$$

Oil prices will be regarded as an exogenous variable:

$$
\mathrm{X}_{\mathrm{t}}=\Delta \log \left(\text { poil }_{t}\right)
$$

The matrix for long-term growth $\mathrm{M}_{\mathrm{t}}$ is defined as:

$$
\mathrm{M}_{\mathrm{t}}=\left[\mu_{t}^{g d p} \mu_{t}^{c o n s} \mu_{t}^{i n v} \mu_{t}^{e x} \mu_{t}^{i m} 0\right]
$$

We assume that the long-run growth rate for GDP, consumption, investment, exports, and imports $\left(\mu_{t}^{g d p}=\mu_{t}^{\text {cons }}=\mu_{t}^{i n v}=\mu_{t}^{e x}=\mu_{t}^{i m}\right)$ is the same, and that long-run growth for the real effective exchange rate equals zero, which would mean that the time series for the real exchange rate do not exhibit a long-run trend. Nevertheless, the real exchange rate is assumed to be non-stationary (the model employs the difference stationary process), and some 'trend' might manifest itself in the time series for the real exchange rate, just as in the classical random walk process. Sustainable appreciation or depreciation of the real exchange rate within a certain timeframe may be observed due to sustainable growth or decline in oil prices or due to the consecutive materialisation of positive or negative shocks from other long-run determinants of the real exchange rate, such as the productivity differential between the traded and non-traded sectors as compared with trade partners. The latter is also known as the Balassa-Samuelson effect (Balassa, 1964; Samuelson, 1964).

We also attempt to factor in the recent slowdown of the Russian economy, which is modelled as a structural break in the parameter vector of unconditional growth rates: 


$$
\mu_{t}^{i}=\left\{\begin{array}{l}
\mu_{0}^{i}, \text { if } t \leq 2007 \mathrm{Q} 3 \\
\mu_{1}^{i}, \text { if } t>2007 \mathrm{Q} 3
\end{array}, i \in\{g d p, \text { cons, inv, ex,im }\}\right.
$$

The date for the structural break was selected based on the results of the econometric analysis by Polbin and Skrobotov (2016). The sensitivity test reveals that the results remain stable in the case of minor adjustments to the date of the structural break.

The model permits any constraints to be placed on long-run growth rates. Later, we will test the hypothesis that there is a common long-run growth rate for GDP, consumption, investment, exports, and imports, i.e. that these indicators will grow at the same pace in the long run provided that oil prices remain unchanged.

We estimate the VAR model without the constant, deducting from the actual time series $Y_{t}$ its long-run growth rate $\mathrm{M}_{\mathrm{t}}$ :

$$
Y_{t}-\mathrm{M}_{\mathrm{t}}=\sum_{i=1}^{p_{Y}} A_{i}\left(Y_{t-i}-M_{\mathrm{t}-\mathrm{i}}\right)+\sum_{j=0}^{p_{X}} B_{j} X_{t-j}+\mathrm{E}_{t},
$$

where $p_{Y}$ and $p_{X}$ are the number of lags of endogenous and exogenous variables respectively, and $\mathrm{E}_{t}$ is the model's random error vector.

We assume that the log of oil prices is a random walk without the constant, and that the best forecast for oil prices is their prior value (Alquist et al., 2013). Therefore, the best forecast for oil price growth will be zero. In this case, in the scenario of constant oil prices, the long-run forecast for vector $Y_{t}$ is $\mathrm{M}_{\mathrm{t}}$, since there is no constant in the model, and the unconditional expectation in the centred series in the righthand expression of the equation is assumed to be zero. The VAR-LASSO model is estimated by minimising the functional (10). We apply prior normalisation of the model's variables with standard errors in endogenous $\sigma_{Y_{t}}$ and exogenous $\sigma_{X_{t}}$ variables:

$$
\begin{gathered}
\sigma_{Y_{t}}=\left[\sigma_{\Delta \log \left(g d p_{t}\right)}, \sigma_{\Delta \log \left(\text { cons }_{t}\right)}, \sigma_{\Delta \log \left(\text { inv }_{t}\right)}, \sigma_{\Delta \log \left(\text { ex }_{t}\right)},\right. \\
\left.\sigma_{\Delta \log \left(\text { im }_{t}\right)}, \sigma_{\Delta \log \left(\text { reer }_{t}\right)}\right], \\
\sigma_{X_{t}}=\sigma_{\Delta \log \left(\text { poil }_{t}\right)} .
\end{gathered}
$$

For the sake of convenience, we will use a single parameter vector $\phi$ :

$$
\begin{gathered}
\Phi=\left[\begin{array}{ll}
A & B
\end{array}\right] ; \phi=\operatorname{vec}\left(\Phi^{T}\right), \\
Q\left(\phi, \mu_{t}\right)=\sum_{s=1}^{k} \sum_{t=1}^{T} E_{s, t}^{2}+\lambda \sum_{i=1}^{k^{2} p_{Y}+k p_{X}}\left|\phi_{i}\right|
\end{gathered}
$$

where $\mathrm{E}_{s, t}$ is the vector of residuals of equation $s$ from model (10), and $\lambda$ is the penalty (tuning) parameter which is responsible for the value of the penalty for extreme values of the coefficients with lags $Y_{t}$ and $X_{t}$. 
After the parameter set has been selected by estimating the VAR-LASSO model with standardised variables, we estimate the VAR model for this parameter set with OLS (OLS post-LASSO estimation).

\section{Model estimation}

\subsection{Accuracy test for the impulse response function estimator based on the VAR-LASSO model}

Before sharing the results of our econometric estimations, we shall examine the VAR-LASSO model's applicability to structural analysis. The model proposed in the present paper links macroeconomic indicators and oil prices. Parameter estimators enable us to build functions for the impulse response of endogenous variables to oil price shocks, which is a natural element of a test of a model's dynamic properties. With the help of LASSO, the OLS technique for the selected set of parameters enables us to lower the bias of the coefficients under estimation and build a confidence interval for the parameters and the impulse response functions (Belloni and Chernozhukov, 2013). However, the use of this procedure for the VAR model may prompt some criticism, since substantiating that the sparse VAR model describes the true process of data generation is virtually impossible (with the exception of substantiation with classical macroeconometric models that consist of simultaneous equations). VAR-LASSO can therefore be regarded only as an attempt to approximate the covariate structure to the true process using a model with few parameters. We will examine how accurate an estimation of the impulse response functions this approximation attempt can provide as part of our Monte Carlo experiments.

In conducting this exercise, we rely on Kilian (2001). The VAR(3) model is taken as the data generation process, following which we calculate how often $68 \%$, $80 \%$, and $90 \%$ VAR-LASSO confidence intervals cover the assumed true impulse response to an oil price shock under the $\operatorname{VAR}(3)$ model. VAR(1) is a competing model that is usually selected based on the BIC information criterion for our data set and duration. We use $\operatorname{VAR}(3)$ pointwise OLS estimators for our data set as parameters for the $\operatorname{VAR}(3)$ model employed to generate pseudo samples. All the models assume a common long-run trend with a break as described in the previous section.

Taking 500 modelled normally-distributed series of errors (a VAR(3)-based estimated covariate matrix is used as a covariate matrix during simulations), we generate 500 data sets and estimate VAR-LASSO and VAR(1) models based on them. In each of the 500 Monte Carlo simulations, we build confidence intervals for impulse responses. Initially, we design a data set that is 100 points longer that the actual sample length (79 points). Subsequently, the first 100 observations are truncated to offset the effect of the initial conditions. The results of both models are presented in Figure 1. 
Figure 1. Coverage of $68 \%, 80 \%$, and $90 \%$ confidence intervals under VAR-LASSO and $\operatorname{VAR}(1)$ for the $\operatorname{VAR}(3)$ model
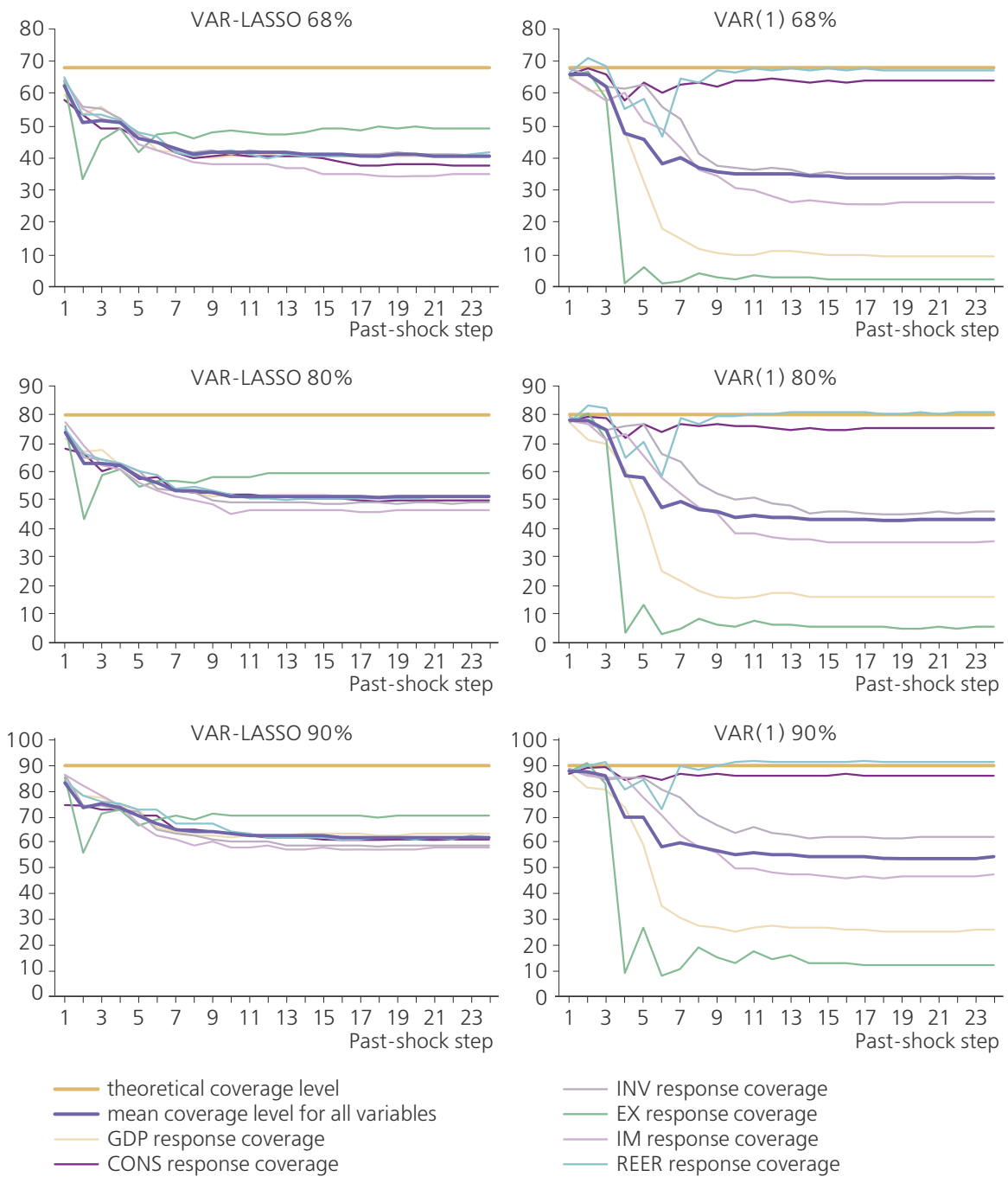

According to Figure 1, the average coverage level across the variables shrinks as the impulse horizon expands. A similar outcome for certain models is found in Kilian (2001). This means that coverage is more often exhibited on the short-run horizon, where the frequency is close to nominal, but the frequency of the coverage of a true response on the longer horizon by the estimated confidence intervals is significantly reduced compared with the nominal frequency.

It is safe to say that the VAR-LASSO results are more stable than those achieved using the VAR(1) model. VAR(1) demonstrates substantially poorer coverage for GDP and exports responses in the medium and long run. For instance, the $68 \%$ confidence interval in the long run covers the true GDP response in fewer than $10 \%$ of cases, and the export response in fewer than $3 \%$ of cases. Nevertheless, VAR(1) 
does an excellent job of covering consumption and real exchange rate responses at every coverage level, with the coverage frequency close to the nominal.

VAR-LASSO covers all responses at all confidence intervals equally well and is on average better than VAR(1). For example, in the case of the $90 \%$ interval on the long-run horizon, the VAR-LASSO coverage level remains around $62 \%$ on average, compared with $54 \%$ for $\operatorname{VAR}(1)$.

The objective of the experiment was to demonstrate the ability of the VAR-LASSO model to estimate the impulse response of the data generation process with at least the same rate of success as the standard VAR model selected with the Schwarz criterion. The impulse response estimators prove quite accurate on the shortrun horizon and exhibit lower accuracy as the horizon expands under both models.

\subsection{Estimation results}

We now move on to the estimation of the VAR-LASSO model based on Russian data. The maximum lag length is one year, i.e. it equals four for endogenous and exogenous variables (the current difference of the log of oil prices is also included). Therefore, each of the six equations features $k p_{Y}+p_{X}=29$ parameters (excluding long-run growth rates). We have a sample of 79 points, and therefore have fewer than three observations per parameter.

To calculate the value of the penalty we perform cross-validation for the last $T_{c v}=16$ sample points (2015Q1-2018Q4) and calculate the total RMSFE for all the endogenous variables with the following formula:

$$
R M S F E=\sqrt{\frac{1}{T_{c v}} \sum_{t=1}^{T_{c v}} \sum_{j=1}^{k}\left(y_{j, t}-\hat{y}_{j, t}\right)^{2}}
$$

where $y_{j, t}$ is the actual value of the $j$-th endogenous variable at time $t$, and $\hat{y}_{j, t}$ is the projected value of the $j$-th endogenous variable at time $t$. The results of the crossvalidation are given in Figure 2. The optimal value of $\lambda=29$.

Figure 2. Cross-validation results for the period 2015Q1-2018Q4

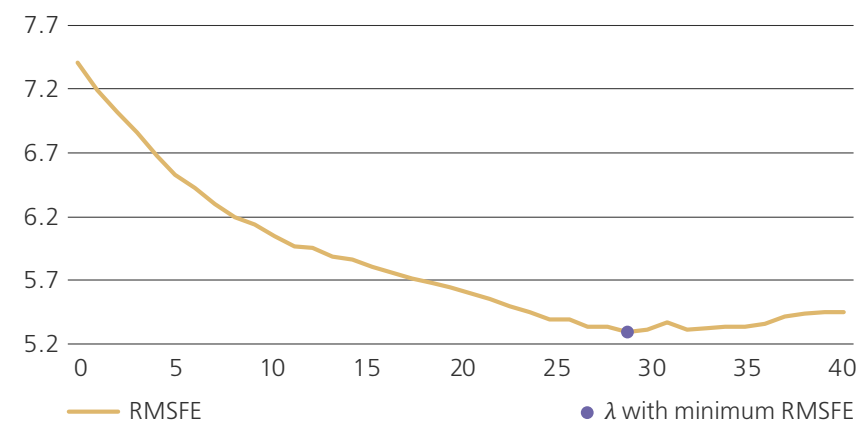


We estimate the model with the selected optimal value of parameter $\lambda$ and re-estimate the model with OLS for a selected number of parameters. This set of parameters will later be used in estimating the model with restricted long-run growth and in testing the hypothesis that the long-run growth rates of the indicators used in the model are the same. We employ the likelihood ratio test, and shall therefore test both the general model and the reduced one. The estimated values of the coefficients are given in Table A1 in the Appendix.

On the basis of the estimated model, we can produce a matrix of long-run multipliers $C$ of the effect of oil prices using matrix polynomials with $L=1$, $A(1)=A_{1}+A_{2}+\ldots+A_{p_{y}}$ и $B(1)=B_{1}+B_{2}+\ldots+B_{p_{x}}$ :

$$
C=B(1) *\left(I_{k}-A(1)\right)^{-1} \text {. }
$$

Matrix $C$, since we have just one exogenous variable, shall consist of one raw with the long-run multiplier of the $j$-th variable for oil prices in the $j$-th position, i.e. the value where the variable impulse response to an oil price shock will be converging.

To test the hypothesis of a common long-run growth rate before and after the structural break in 2007Q3, we shall estimate the VAR-LASSO model and the VAR(1) model with and without the constraint using the likelihood ratio (LR) test. The null hypothesis can be presented as eight linear constraints:

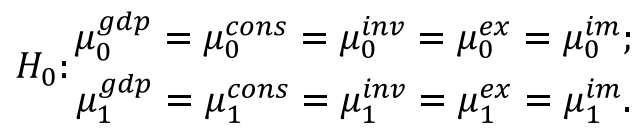

In other words, we are testing the hypothesis $H_{0}$ that long-run growth in GDP, consumption, investment, exports, and imports was the same before and after the structural break in 2007Q3, but the hypothesis does not suggest that there was no structural break at all. An alternative hypothesis suggests that at least one of the constraints is not valid. The results of the LR test are given in Table 2.

Table 2. Results of the LR test

\begin{tabular}{cc} 
Model & P-value \\
\hline VAR-LASSO & 0.0585 \\
\hline $\operatorname{VAR}(1)$ & 0.0387 \\
\hline
\end{tabular}

The LR test does not rule out the null hypothesis at the 5\% level for VAR-LASSO. The caveat is that the criticism of hypothesis tests for sparse VAR models explained in Section 3.1 is also valid for the LR test, so its results should be treated with caution. Table 2 gives the results of the test of the standard non-sparse VAR(1) model selected on the basis of the BIC. The p-value for the hypothesis in the VAR(1) model is $3.87 \%$.

The sparsity pattern with OLS post-LASSO estimators of the model with a common long-run growth rate is presented in Table A1 in the Appendix. Multipliers are calculated for oil prices for the variables of interest under the model with 
a common long-run growth rate, and are presented in Table 3.

Table 3. Matrix of long-run multipliers for oil prices in the model with a common long-run growth rate

\begin{tabular}{c|ccc|}
\hline Variable & GDP & Consumption & Investment \\
\hline & 0.0896 & 0.1311 & 0.2121 \\
Multiplier estimator & $(0.0688 ; 0.1122)$ & $(0.0909 ; 0.1728)$ & $(0.1545 ; 0.2864)$ \\
& {$[0.0667 ; 0.1186]$} & {$[0.0829 ; 0.1810]$} & {$[0.1450 ; 0.2966]$} \\
Variable & Exports & Imports & Exchange rate \\
\hline \multirow{2}{*}{ Multiplier estimator } & -0.0102 & 0.3960 & 0.1246 \\
& $(-0.0640 ; 0.0444)$ & $(0.3033 ; 0.4921)$ & $(0.0212 ; 0.2156)$ \\
\hline
\end{tabular}

Note: numbers in parentheses and brackets stand for the $90 \%$ and $95 \%$ asymptotic confidence intervals respectively.

The 0.09 estimate for long-run oil price elasticity of GDP is similar to the 0.1 observed in domestic papers by Polbin and Skrobotov (2016) and Polbin (2017b). Papers by Rautava (2004), Beck et al. (2007), and Kuboniwa (2014) produce an oil price elasticity of GDP of 0.2 , which is significantly higher than our estimate. Pestova and Mamonov (2016b) also study oil price shocks, but with their specification, the GDP response approaches zero over time. Polbin (2017b), which we mentioned earlier, also produces multipliers for consumption and investment of 0.3 and 0.25 respectively. Our multiplier estimator for investment is fairly similar, while our consumption multiplier differs by a factor of 2.3. Estimates for the longrun oil price elasticity of the real exchange rate vary considerably in the Russian economic literature. In more or less comparable samples, Bozhechkova and Trunin (2016) produce 0.17 for 1999-2014Q2, Polbin (2017a) comes up with 0.33 for 1999-2016M11, and Skrobotov and Fokin (2018) get 0.44 for 1999-2014M10. For the constructed confidence intervals, the long-run oil price elasticity of exports is statistically insignificant at the $90 \%$ level.

The estimates for the common long-run growth rate taking into account the structural break are given in Table 4.

Table 4. Estimates for the common long-run growth rate

\begin{tabular}{cc} 
& Common long-run growth rate \\
\hline$\mu_{0}$, & 0.0161 \\
$t \leq 2007 \mathrm{Q} 3$ & $(0.0137 ; 0.0185)$ \\
& {$[0.0132 ; 0.0190]$} \\
$\mu_{1}$, & 0.0042 \\
$t>2007 \mathrm{Q} 3$ & $(0.0024 ; 0.0060)$ \\
\hline
\end{tabular}

Note: numbers in parentheses and brackets stand for the $90 \%$ and $95 \%$ asymptotic confidence intervals, respectively.

According to the estimates in Table 4, long-run growth for GDP, consumption, investment, exports, and imports slowed by a factor of almost four following the structural break, to the current annual rate of $1.68 \%$. This result suggests that, without external shocks, e.g. given constant oil prices, the model would see the Russian economy grow at an annual rate of $1.68 \%$ in the long run, which is definitely not sufficient to 
propel Russia into the top five world economies by GDP at purchasing power parity.

Impulse responses for the model with a common long-run growth rate are given in Figure 3.

Figure 3. Impulse responses of centred variables at levels

to a permanent $10 \%$ oil price shock under the VAR-LASSO model

with a break and a common long-run growth rate
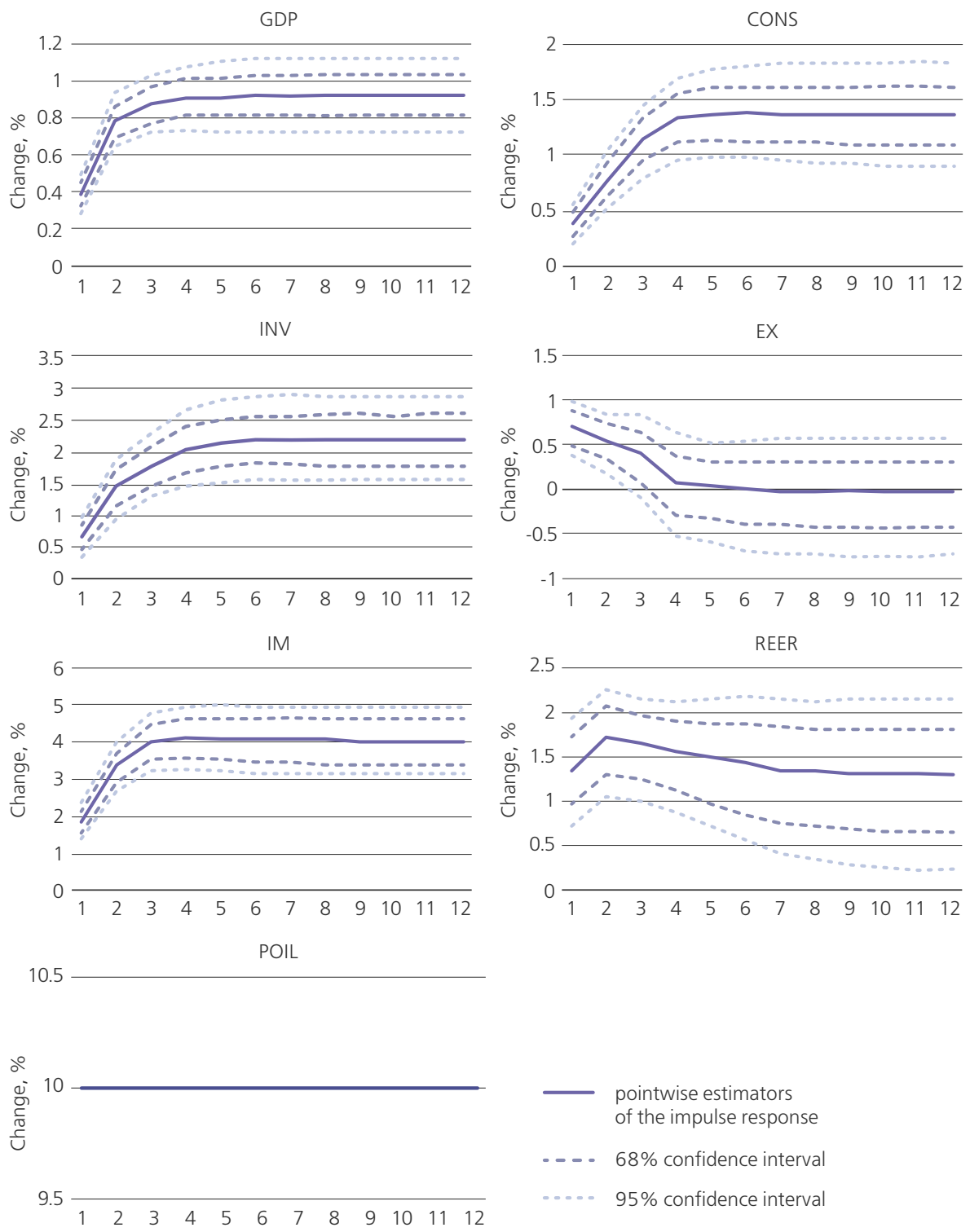

As Figure 3 indicates, the short-run export response to oil prices is positive and statistically significant, while the long-run response is insignificant. It is 
probable that the export response approaches zero as a result of appreciation of the rouble and a subsequent decrease in the competitiveness of Russian exports. GDP, consumption, investment, and imports routinely adjust to the new long-run level, and their responses prove to be statistically significant even at the $95 \%$ level.

Finally, Figure 4 presents the actual growth rates of the indicators and the contribution of long-run growth rates and oil price changes calculated under the model.

Figure 4. Contribution of long-run growth rates and oil prices to changes in the model's variables
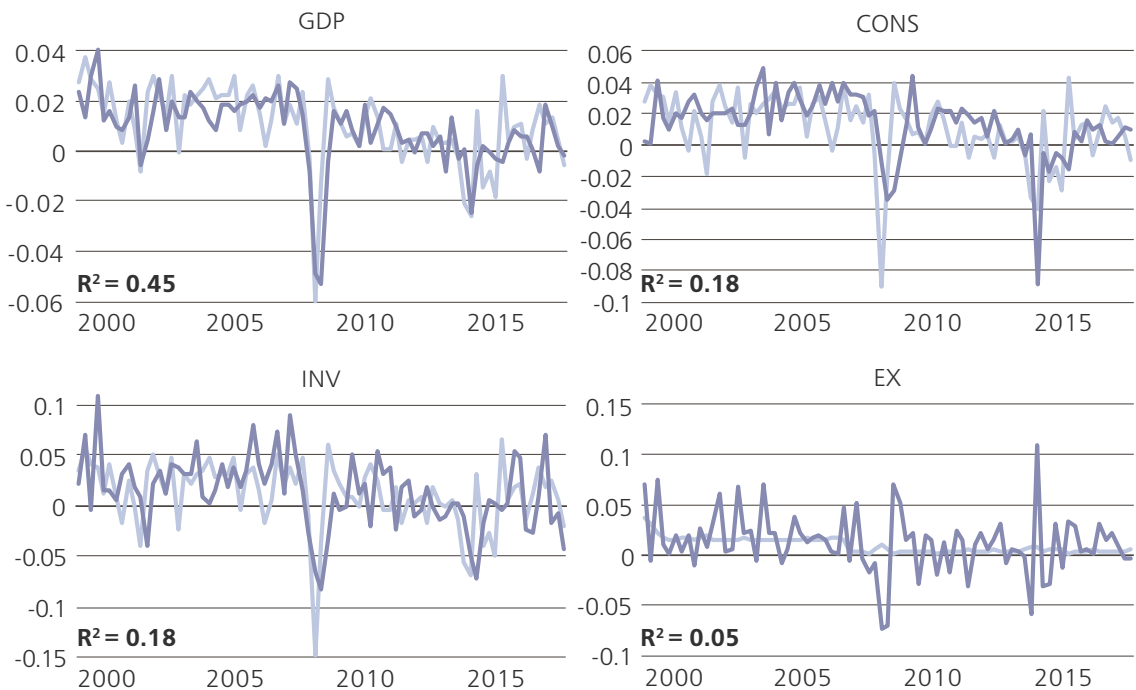

IM
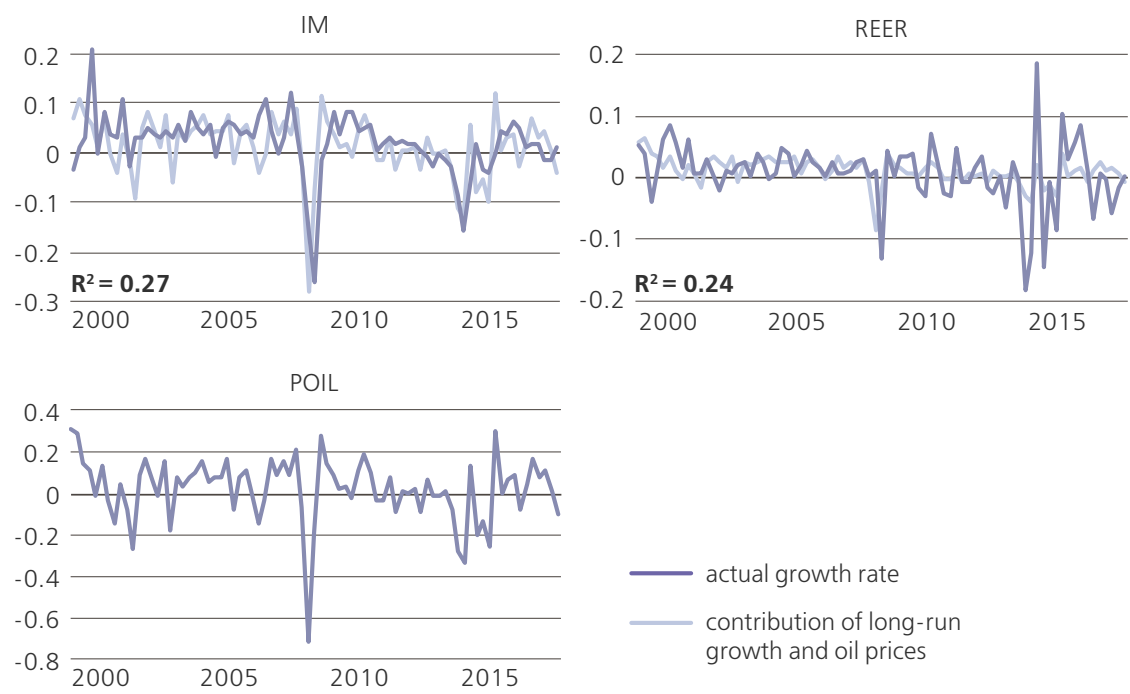
According to Figure 4, the long-run growth rate and oil price shocks provide a fairly clear explanation of the changes in all the model's variables except for export growth, with $R^{2}$ for export growth as low as 0.05 . It is worth remembering that, under the model, the response of exports to oil prices becomes insignificant as early as four quarters after the shock. Therefore, oil price changes do not provoke any substantial changes in exports. Export growth, however, is quite volatile, but the figure suggests that its substantial fluctuations are due to other shocks. For the remaining variables, $R^{2}$ takes quite satisfactory values. The GDP equation exhibits the highest $R^{2}$. The model does a fairly good job of capturing the 2008-2009 and 2015 recessions. In the case of GDP, in-sample estimates of the economic decline are very close to the actual figures during both crises; the same applies to imports. In the case of consumption, the model forecasts a much deeper decline in 2008-2009 than the actual numbers show, while in 2015, according to the model, consumption falls by only half the actual decline. The reason for this might be the substantial fiscal stimulus applied during the 2008-2009 crisis that supported household consumption despite a slump in output. There were no major fiscal stimulus during the latest crisis, and depreciation took a toll on the population's purchasing capacity.

In the case of investment, the model overestimates the depth of recession in 2008-2009, but not as dramatically as in the case of consumption. The 2015 downturn is fairly close to the actual figures, but projected to occur slightly earlier than it in fact did. In the case of the rouble real effective exchange rate, which was a managed nominal exchange rate arrangement before 2015, we observed quite a low level of volatility of the actual exchange rate compared with the inflation-targeting regime introduced since 2015. However, the model does not factor in the change in monetary policy, so the volatility of the in-sample forecast remains unchanged throughout the entire period. In connection with this, the chart indicates that the in-sample forecast explains a higher proportion of the variance before 2015 than it does after 2015. Also, the model presents quite an accurate forecast of the extent of the 2008-2009 rouble depreciation, but identifies its starting point slightly earlier than it in fact occurred, since the Bank of Russia was pursuing a smooth depreciation at the time.

One possible explanation for the high $R^{2}$ values in the experiment presented in Figure 4 could be a simultaneous sharp drop in endogenous macroeconomic indicators and oil prices during the 2008 crisis, which could be interpreted as an 'outlier' rather than a structural linkage. To perform a robustness test on this 'outlier', we also calculated the squared correlation between the actual growth rates of all the variables and the contribution of the long-run growth rate and oil prices in a model with a dummy variable equal to one in 2008Q3, the quarter with the greatest decline in oil prices, which produced determination coefficients with values similar to the original ones. 


\section{Forecasting}

\subsection{Benchmarking GDP forecasts against projections by the MED and BVAR by Pestova and Mamonov (2016b)}

In an effort to demonstrate the predictive power of the VAR-LASSO model, we build a pseudo out-of-sample forecast of GDP growth in 2016-2017 and compare it with the forecasts by the MED and Pestova and Mamonov's BVAR model (2016b). The last point of the training sample is 2015Q4, as in the competing models. Crossvalidation is performed for the last eight points of the sample, 2014Q1-2015Q4. Cross-validation yields the value of parameter $\lambda=29$, which is then fed into the model for a test on the entire sample (1999Q2-2015Q4) that produces a forecast under two oil price scenarios, the baseline and the conservative. In the conservative scenario, the nominal oil price is assumed to be USD 40 per barrel for the entire period, while the baseline scenario sets the oil price at USD 50 per barrel in 2016 and USD 52 per barrel in 2017. The forecasts in the conservative scenario are presented in Figure 5, and the forecasts in the baseline scenario are given in Figure 6.

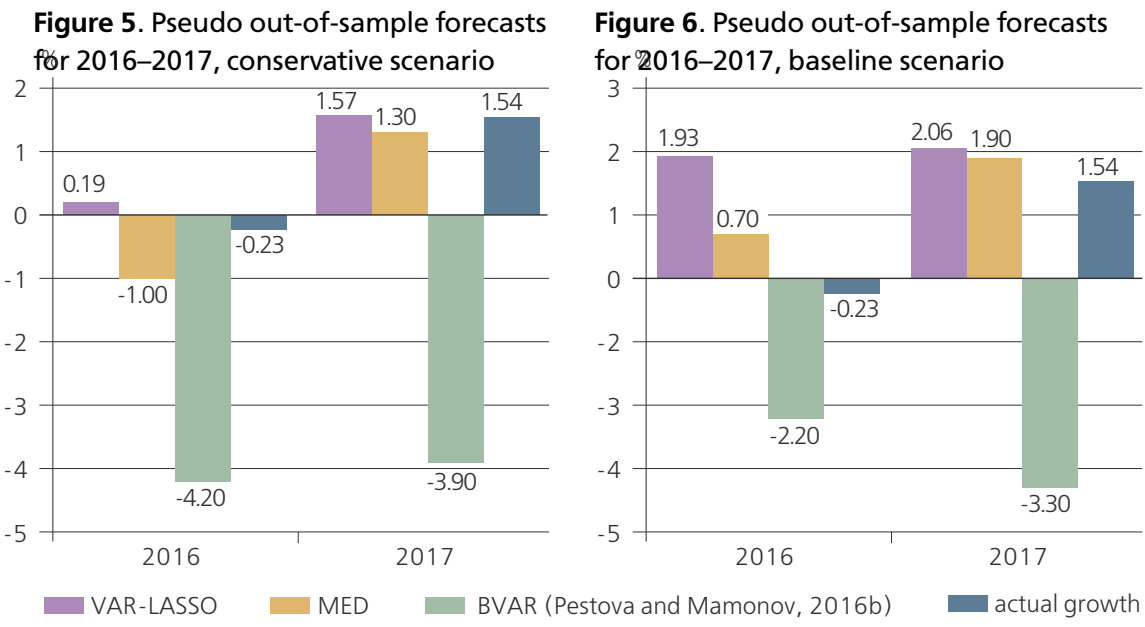

According to the figures, the most accurate of the three scenarios would have been the conservative one if it had been produced back in 2015. The pooled error of the VAR-LASSO forecast over the two years is $0.45 \%$. The MED forecast ranked second for accuracy with a pooled error of $1.01 \%$ over the two years, making the forecasting accuracy of the VAR-LASSO model twice that of the MED forecast. In the baseline scenario, our forecast is less accurate than the MED forecast, again by a factor of two: VAR-LASSO's error over the two years is $2.67 \%$, compared with $1.29 \%$ for the MED over the same two-year period. 


\subsection{Formal statistical comparison}

\section{of VAR-LASSO forecasts across all variables} with the $\operatorname{VAR}(1)$ and ARIMA models

The present section describes our test of the hypothesis that the VAR-LASSO model is capable of delivering better forecasts than alternative models that include the baseline ARIMA model, with lags selected based on the Schwarz criterion, and the VAR(1) model. The VAR(1) model will factor in the same constraints on long-run growth as the VAR-LASSO model, enabling us to establish whether it is the parameter sparsity generated by the LASSO procedure that is responsible for the superior forecasting accuracy of our time series. In general, the VAR(1) model without constraints proves to be inferior to the model with constraints, but the big picture does not change much as far as the test results for the VAR(1) model without constraints are concerned, and for brevity's sake we will not describe it here. The hypothesis on the equal means of VAR-LASSO and other benchmarks' errors is tested with the classical F-test, the sign test, and Wilcoxon's signed-rank test (Wilcoxon, 1945).

On the basis of the RMSE pointwise values in Table 5, VAR-LASSO proves to be the best model at step one and two of the GDP forecast, while VAR(1) ranks first on the last two steps. A similar situation is obtained for consumption and investment: VAR-LASSO surpasses VAR(1) at the first two steps and at the first and third steps, respectively. Export and real exchange rate forecasts are more accurate under the ARIMA model. In the case of imports, accuracy varies between the models depending on the step of the forecast; VAR-LASSO proves the best when the horizon is equal to two.

Table 5. RMSFE values

\begin{tabular}{|c|c|c|c|c|c|c|c|c|c|}
\hline & \multicolumn{3}{|c|}{ GDP } & \multicolumn{3}{|c|}{ Consumption } & \multicolumn{3}{|c|}{ Investment } \\
\hline & $\begin{array}{l}\text { VAR- } \\
\text { LASSO }\end{array}$ & $\operatorname{VAR}(1)$ & ARIMA & $\begin{array}{l}\text { VAR- } \\
\text { LASSO }\end{array}$ & $\operatorname{VAR}(1)$ & ARIMA & $\begin{array}{l}\text { VAR- } \\
\text { LASSO }\end{array}$ & $\operatorname{VAR}(1)$ & ARIMA \\
\hline$h=1$ & 0.007 & 0.0085 & 0.0079 & 0.0123 & 0.0199 & 0.0192 & 0.0366 & 0.0367 & 0.0398 \\
\hline$h=2$ & 0.0071 & 0.0072 & 0.0088 & 0.0081 & 0.0092 & 0.0164 & 0.0331 & 0.0326 & 0.0369 \\
\hline$h=3$ & 0.0079 & 0.0067 & 0.0086 & 0.0106 & 0.0088 & 0.0175 & 0.0331 & 0.0341 & 0.0350 \\
\hline \multirow[t]{3}{*}{$h=4$} & 0.0085 & 0.0066 & 0.0085 & 0.0108 & 0.0084 & 0.0157 & 0.0337 & 0.0334 & 0.0341 \\
\hline & \multicolumn{3}{|c|}{ Exports } & \multicolumn{3}{|c|}{ Imports } & \multicolumn{3}{|c|}{ Exchange rate } \\
\hline & $\begin{array}{l}\text { VAR- } \\
\text { LASSO }\end{array}$ & $\operatorname{VAR}(1)$ & ARIMA & $\begin{array}{l}\text { VAR- } \\
\text { LASSO }\end{array}$ & $\operatorname{VAR}(1)$ & ARIMA & $\begin{array}{l}\text { VAR- } \\
\text { LASSO }\end{array}$ & $\operatorname{VAR}(1)$ & ARIMA \\
\hline$h=1$ & 0.0269 & 0.0298 & 0.0209 & 0.0328 & 0.0345 & 0.0275 & 0.0912 & 0.0931 & 0.0791 \\
\hline$h=2$ & 0.0237 & 0.0228 & 0.0179 & 0.0301 & 0.0343 & 0.0339 & 0.082 & 0.0664 & 0.0653 \\
\hline$h=3$ & 0.019 & 0.0154 & 0.0147 & 0.0340 & 0.0321 & 0.0304 & 0.0634 & 0.0565 & 0.0542 \\
\hline$h=4$ & 0.0169 & 0.0172 & 0.0144 & 0.0327 & 0.0299 & 0.0316 & 0.0581 & 0.0537 & 0.0563 \\
\hline
\end{tabular}

Note: the figures in bold are the lowest RMSFE values from VAR-LASSO, VAR(1), and ARIMA at each of the forecast steps.

We build pseudo out-of-sample forecasts under the three models for 
the past four years (16 points) four steps ahead. Furthermore, to expand the number of 'observations' for the tests, we incorporate 54 forecast errors across different horizons under one model as a single stack without horizon differentiation.

The test results (p-value) of VAR-LASSO versus VAR(1) and ARIMA are presented in Tables 6 and 7 respectively.

Table 6. Results of an equal means test for forecasting errors in VAR-LASSO versus VAR(1)

\begin{tabular}{|c|c|c|c|c|c|c|}
\hline Test & GDP & Consumption & Investment & Exports & Imports & $\begin{array}{c}\text { Exchange } \\
\text { rate }\end{array}$ \\
\hline Sign test & 0.3927 & 0.6073 & $0.0512^{*}$ & 0.2931 & 0.7069 & 0.8619 \\
\hline $\begin{array}{c}\text { Signed-rank } \\
\text { test }\end{array}$ & 0.7422 & 0.4232 & 0.1621 & 0.7477 & 0.8482 & 0.9706 \\
\hline F-test & 0.2384 & $0.0206^{\star *}$ & 0.3982 & 0.3693 & 0.3151 & 0.5872 \\
\hline
\end{tabular}

Note: ${ }^{* *}-\mathrm{p}<0.01 ;^{* *}-\mathrm{p}<0.05 ;^{*}-\mathrm{p}<0.1$.

Table 7. Results of an equal means test for forecasting errors in VAR-LASSO versus ARIMA

\begin{tabular}{c|ccc|cc|c}
\hline Test & GDP & Consumption & Investment & Exports & Imports & $\begin{array}{c}\text { Exchange } \\
\text { rate }\end{array}$ \\
\hline Sign test & 0.1381 & $0.0000^{* * *}$ & $0.0283^{* *}$ & 0.9488 & 0.7069 & 0.9132 \\
\hline $\begin{array}{c}\text { Signed-rank } \\
\text { test }\end{array}$ & $0.0643^{*}$ & $0.0001^{* * *}$ & 0.2388 & 0.9940 & 0.9357 & 0.9972 \\
\hline F-test & $0.0583^{*}$ & $0.0000^{* * *}$ & 0.2049 & 0.5912 & 0.3645 & 0.6542 \\
\hline
\end{tabular}

Note: ${ }^{* *}-\mathrm{p}<0.01 ;{ }^{* *}-\mathrm{p}<0.05 ;{ }^{*}-\mathrm{p}<0.1$

In terms of statistical significance, the test results demonstrate that VARLASSO is superior to $\operatorname{VAR}(1)$ forecasts in two cases only: in the case of the F-test for consumption, and in the case of the sign test for investment. VAR-LASSO is somewhat better than ARIMA. The signed-rank test and the F-test reject the equal means hypothesis for the GDP forecast errors at the $10 \%$ level. All the tests refute the equal means hypothesis for consumption at any reasonable level of significance, and the sign test refutes the null hypothesis for investment. However, none of the tests reject the null hypothesis for exports, imports, and the exchange rate.

\subsection{Scenario forecasts for $2019-2024$}

We now move on to the forecasts for 2019-2024. Aside from the MED forecast (2018), we will also benchmark our forecasts with the IMF (2018) and WB (2018) projections to provide broader coverage of domestic and international experts' expectations for Russia's growth.

The MED has two oil scenarios in its forecast, the baseline and the conservative. Oil price changes for both scenarios are presented in Figure 7.

Figure 7. Oil prices in the baseline and conservative scenarios

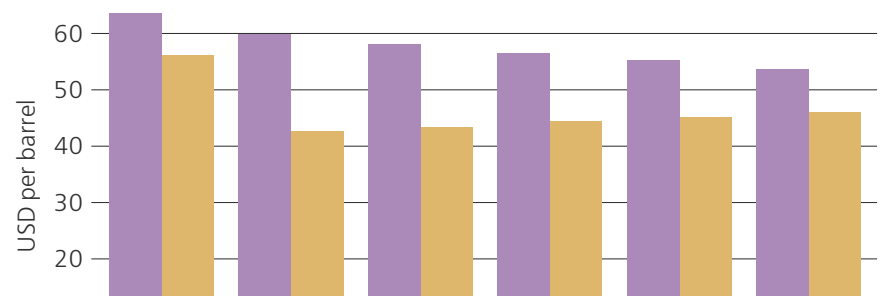


The IMF (2018) and the WB (2018) have a similar oil price scenario for 20192024. According to the IMF, the average oil price for UK Brent, Dubai Fateh, and WTI is expected to be USD 68.76 per barrel in 2019. The IMF publishes Russia's GDP growth figures to 2023, so we will use the nominal oil price of USD 68.76 per barrel for 2019-2023 for the sake of comparison. The WB projects the average prices for the same benchmark oils at USD 71 per barrel in 2019-2020.

A comparison of the GDP growth forecast with the MED forecasts is presented in Figure 8. VAR-LASSO forecasts for GDP and other indicators are also given in the Appendix. Table A2 provides baseline forecasts, while Table A3 features conservative scenario projections.

Figure 8. VAR-LASSO and MED forecasts in the MED baseline and conservative scenarios

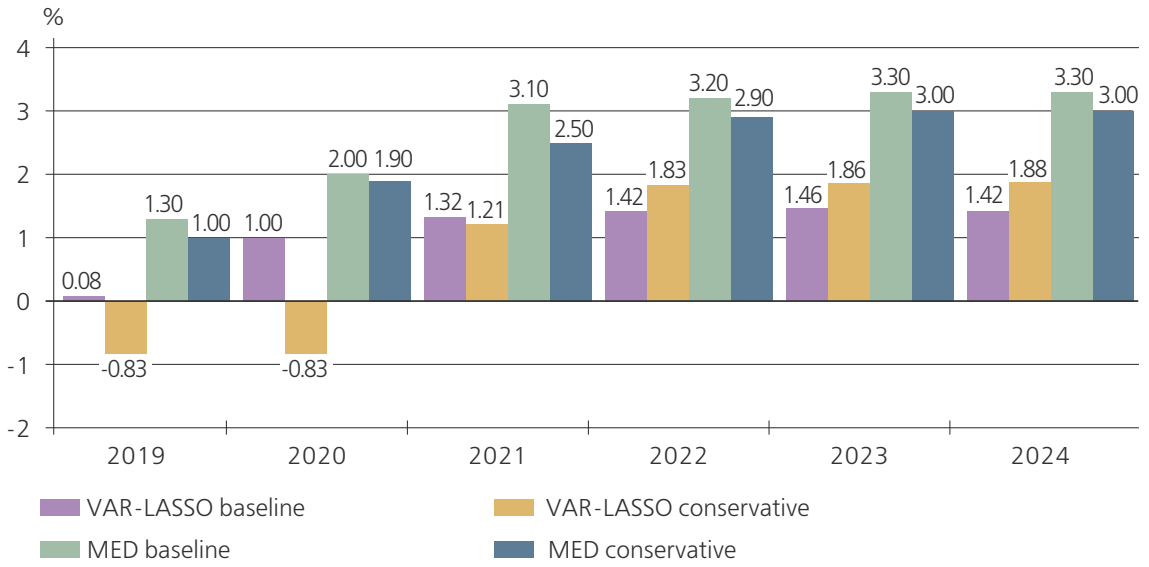

The VAR-LASSO forecast for the baseline scenario in 2019 and 2020 is lower than the long-run annual growth rate of $1.7 \%$ due to the reduction in oil prices compared to 2018. GDP growth is projected to be close to zero in 2019 if oil prices fall to USD 63 per barrel as indicated in the scenario. The MED also forecasts a relatively slow growth rate in 2019 as opposed to future periods. From 2022, the forecast will stabilise at an annual level of around $1.4 \%$. In the conservative scenario, the VAR-LASSO model forecasts a recession in 2019 and 2020 at $-0.83 \%$ and $-0.83 \%$ respectively due to a strong decline in oil prices, from USD 71 in 2018 to USD 56 in 2019 and USD 42.5 in 2020. Consumption, investment, and exports in this scenario fall substantially lower than GDP, but imports also shrink drastically, which makes the GDP drop look smaller than the decrease in the other variables. By 2021, growth is projected to stabilise at a yearly average of $1.86 \%$ in the conservative scenario, i.e. growth will be even faster than in the baseline scenario. However, according to our model, given the slumps in 2019 and 2020, GDP in the fourth quarter of 2024 will be $1.5 \%$ higher in the baseline scenario than GDP in the fourth quarter of 2024 in the conservative scenario.

Figure 9. IMF, WB, and VAR-LASSO forecasts under IMF and WB scenarios 


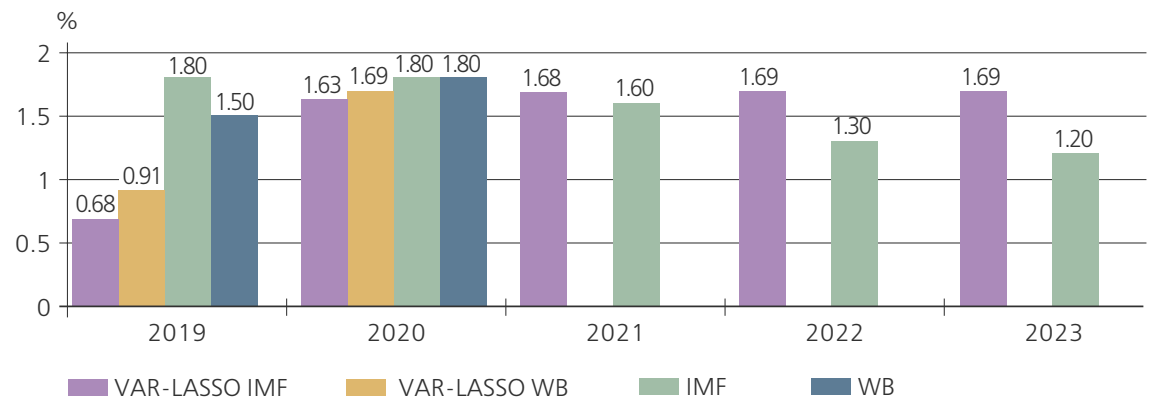

The MED growth forecast is substantially higher than the forecast under the VAR-LASSO model. According to the MED, the Russian economy is expected to reach growth above $3 \%$ as early as 2021 amid consistently falling oil prices in the baseline scenario. In the conservative scenario, growth above $3 \%$ is expected to be achieved by 2023. The MED forecasts most likely factor in an acceleration of longrun growth as a result of structural reforms in the next two years that are expected to boost the economy by a factor of 1.5. Our specification cannot explicitly take into account the impact of any reforms, e.g. a VAT increase, the pension reform, etc., on long-run growth. However, these effects can be incorporated implicitly with the long-run growth parameter $\mu_{t}$ provided that there is a quantitative estimate of the effect from a particular reform. We can assume that long-run growth will reach $2 \%$, not $1.7 \%$, and that the additional $0.3 \%$ will come from an earlier reform. Figure 9 presents forecasts by the VAR-LASSO model under the IMF and WB scenarios and the international institutions' own forecasts (2019-2023 for the IMF and 2019-2020 for the WB).

For 2019, there is a clear difference - of more than $1 \%$ - between our forecast and the IMF projections, while the gap between our forecast and the WB forecast is $0.6 \%$. For 2020, the forecast by the VAR-LASSO model and the IMF and WB forecasts are very close, at $1.63-1.69 \%$ versus $1.8 \%$. The VAR-LASSO forecast subsequently stabilises at the level of the long-run growth rate in 2021-2023, while the IMF forecast figures get lower every year, from $1.6 \%$ in 2021 down to $1.2 \%$ in 2023 . The IMF's conclusion is that, given constant oil prices, the Russian economy's long-run growth will decline. Forecasts for GDP and other indicators in 2019-2024 in the IMF and WB scenarios are presented in Tables A4 and A5 of the Appendix respectively.

The IMF and MED forecasts for 2021-2024 exhibit different trends, with the IMF forecast being pessimistic compared with the VAR-LASSO forecast and the MED being optimistic, despite its prediction of much lower oil prices. Thus, the VAR-LASSO model's forecast proves to be closer to projections by international financial institutions than to the MED projection.

\section{Conclusion}


This paper has presented a VAR-LASSO model to forecast growth in GDP, household consumption, fixed asset investment, exports, imports, and the real effective exchange rate amid the Russian economy's slowdown following the 2008 crisis. The model is built on the assumption that GDP and its components had a common long-run growth rate both before the structural break and after it. Under the model, the Russian economy is expected to exhibit an annual long-run growth rate of $1.68 \%$. The quality of the VAR-LASSO forecasts was tested in a pseudo outof-sample benchmarking experiment against the MED forecast and the forecast by Pestova and Mamonov's BVAR model (2016b) for 2016 and 2017 in two MED scenarios. The model yielded the best result for the conservative scenario and ranked second for the baseline scenario. The pseudo out-of-sample forecasting experiments also demonstrated that, for some variables, the VAR-LASSO model provides more accurate forecasts in statistical significance terms than ARIMA and VAR(1). However, the statistically significant improvement in the forecast does not apply to all the variables, which may be due both to the equivalent predictive capability of the alternative models and to the low power of the corresponding tests for short samples.

The paper has also provided a growth forecast for GDP and its components in 2019-2024 for the MED baseline and conservative oil price scenarios, as well as for the IMF and WB oil price scenarios. The VAR-LASSO model produces a neutral forecast compared with the benchmarks. In the long run, it is not as optimistic as the MED forecast (above 3\% from 2021 amid falling oil prices) and not as pessimistic as the IMF forecast (1.2-1.3\% in 2022-2023 given constant oil prices).

\section{References}

Alquist, R., Kilian, L. and Vigfusson, R. J. (2013). Forecasting the Price of Oil. Handbook of Economic Forecasting, Vol. 2. Elsevier, pp. 427-507.

Astafieva, E. and Turuntseva, M. (2014). Forecasting Using Large Data Sets. Russian Presidential Academy of National Economy and Public Administration Working Papers. [In Russian]. doi: 10.2139/ssrn.2429906

Ayvazyan, S., Brodskiy, B., Sandoyan, E., Voskanyan, M. and Manukyan, D. (2013). Macroeconometric Modeling of Russian and Armenian Economies. Applied Econometrics, 30(2), pp. 85-111. [In Russian].

Balassa, B. (1964). The Purchasing-Power Parity Doctrine: A Reappraisal. Journal of Political Economy, 72(6), pp. 584-596.

Baybuza, I. (2018). Inflation Forecasting Using Machine Learning Methods. Russian Journal of Money and Finance, 77(4), pp. 42-59.

Beck, R., Kamps, A. and Mileva, E. (2007). Long-Term Growth Prospects for the Russian Economy. ECB Occasional Paper, N 58.

Belloni, A. and Chernozhukov, V. (2013). Least Squares after Model Selection in High-dimensional Sparse Models. Bernoulli, 19(2), pp. 521-547.

Bozhechkova, A. and Trunin, P. (2016). Analysis of Factors Affecting the Dynamics 
of the Real Ruble Exchange Rate. Moscow: Delo Publishing House of the RANEPA. [In Russian]. Available at: https://www.ranepa.ru/images/docs/nayka/delo/ Trunin_blok.pdf [accessed on 23 May 2019].

Breiman, L. (1995). Better Subset Regression Using the Nonnegative Garrote. Technometrics, 37(4), pp. 373-384.

Davis, R. A., Zang, P. and Zheng, T. (2016). Sparse Vector Autoregressive Modeling. Journal of Computational and Graphical Statistics, 25(4), pp. 1077-1096.

Demeshev, B. and Malakhovskaya, O. (2015). A Comparison of Random Walk, $V A R$, and Litterman's BVAR Models for Forecasting Output, Price Index, and Interest Rate. National Research University Higher School of Economics Working Paper, N WP12/2015/03. [In Russian]. Available at: https://wp.hse.ru/ data/2015/12/19/1134100841/WP12_2015_03_ff.pdf [accessed on 23 May 2019].

Deryugina, E. and Ponomarenko, A. (2015). A Large Bayesian Vector Autoregression Model for Russia. Bank of Russia Working Paper Series, N 1.

Drobyshevsky, S., Kadochnnikov, P. and Ponomarenko, S. (2005). Medium-term Macroforecast for Russia Based on Structural Econometric Equations. In: Some Approaches to Forecasting of Economic Indicators. Moscow: IET, pp. 104-143. [In Russian]. Available at: https://www.iep.ru/files/text/working_papers/89.pdf.

Fokin, N. (2019). VAR-LASSO Model for the Russian Economy Using a Large Dataset. Russian Economic Developments, 26(1), pp. 20-30. [In Russian]

Gefang, D. (2014). Bayesian Doubly Adaptive Elastic-Net LASSO for VAR Shrinkage. International Journal of Forecasting, 30(1), pp. 1-11.

Hsu, N. J., Hung, H. L. and Chang, Y. M. (2008). Subset Selection for Vector Autoregressive Processes Using LASSO. Computational Statistics and Data Analysis, 52(7), pp. 3645-3657.

International Monetary Fund (2018). World Economic Outlook: Challenges to Steady Growth. Washington, DC, October.

Ivashchenko, S. (2013). Dynamic Stochastic General Equilibrium Model with Banks and Endogenous Defaults of Firms. Journal of the New Economic Association, 19(3), pp. 27-50. [In Russian].

Kilian, L. (2001). Impulse Response Analysis in Vector Autoregressions with Unknown Lag Order. Journal of Forecasting, 20(3), pp. 161-179.

Kreptsev, D. and Seleznev, S. (2016). DSGE Model of the Russian Economy with Small Number of Equations. Bank of Russia Working Paper Series, N 12. [In Russian]. Available at: https://www.cbr.ru/Content/Document/File/16728/wps_12.pdf [accessed on 23 May 2019].

Kuboniwa, M. (2014). A Comparative Analysis of the Impact of Oil Prices on Oil-Rich Emerging Economies in the Pacific Rim. Journal of Comparative Economics, 42(2), pp. 328-339.

Li, J. and Chen, W. (2014). Forecasting Macroeconomic Time Series: LASSO-based Approaches and Their Forecast Combinations with Dynamic Factor Models. International Journal of Forecasting, 30(4), pp. 996-1015. 
Malakhovskaya, O. (2016). DSGE-based Forecasting: What Should Our Perspective Be? Voprosy Ekonomiki, 12, pp. 129-146. [In Russian]. doi: 10.32609/0042-8736-2016-12-129-146

Mikhailenko, K. (2005). Economic-Mathematical Support of the Medium-term Forecast Scenarios of the Social-Economic Development of Russia. PhD thesis. [In Russian]. Available at: http://www.forecast.ru/_ARCHIVE/Dissert/Kmikhailenko/AR10.pdf [accessed on 23 May 2019].

Mikosch, H. and Solanko, L. (2019). Forecasting Quarterly Russian GDP Growth with Mixed-Frequency Data. Russian Journal of Money and Finance, 78(1), pp. 19-35.

Ministry of the Economic Development of the Russian Federation (2018). Forecast of the Social-Economic Development of the Russian Federation up to 2024. [In Russian]. Available at: http://economy.gov.ru/minec/activity/sections/macro/201801101 [accessed on 23 May 2019].

Nicholson, W. B., Matteson, D. S. and Bien, J. (2017). VARX-L: Structured Regularization for Large Vector Autoregressions with Exogenous Variables. International Journal of Forecasting, 33(3), pp. 627-651.

Pestova, A. and Mamonov, M. (2016a). A Survey of Methods for Macroeconomic Forecasting: Looking for Perspective Directions in Russia. Voprosi Ekonomiki, (6), pp.45-75. [In Russian]. doi: 10.32609/0042-8736-2016-6-45-75

Pestova, A. and Mamonov, M. (2016b). Estimating the Influence of Different Shocks on Macroeconomic Indicators and Developing Conditional Forecasts on the Basis of BVAR Model for the Russian Economy. Economic Policy, 11(4), pp. 56-92. [In Russian].

Polbin, A. (2017a). Modeling the Real Ruble Exchange Rate under Monetary Policy Regime Change. Voprosy Ekonomiki, 4, pp. 61-78. [In Russian]. doi: 10.32609/0042-8736-2017-4-61-78

Polbin, A. (2017b). Econometric Estimation of the Impact of Oil Prices Shock on the Russian Economy in VECM Model. Voprosy Ekonomiki, 10, pp. 27-49. [In Russian]. doi: 10.32609/0042-8736-2017-10-27-49

Polbin, A. and Skrobotov, A. (2016). Testing for Structural Breaks in the Long-run Growth Rate of the Russian Economy. HSE Economic Journal, 20(4), pp. 588-623. [In Russian]

Porshakov, A., Ponomarenko, A. and Sinyakov, A. (2016). Nowcasting and Shortterm Forecasting of Russian GDP with a Dynamic Factor Model. Journal of the New Economic Association, 2(30), pp. 60-76. [In Russian]

Rautava, J. (2004). The Role of Oil Prices and the Real Exchange Rate in Russia's Economy A Cointegration Approach. Journal of Comparative Economics, 32(2), pp. 315-327.

Samuelson, P. A. (1964) Theoretical Notes on Trade Problems. The Review of Economics and Statistics, 46(2), pp. 145-154.

Skrobotov, A. and Fokin, N. (2018). Testing Asymmetric Convergence of the Real Exchange Rate to Equilibrium During Ruble Exchange Rate Targeting. Economic Policy, 13(3), pp. 132-147. [In Russian]

Skrobotov, A. and Turuntseva, M. (2015). Forecast Characteristics of VAR-models Application to Russian Data. Gaidar Institute Newsletter.ru, 8(90), pp. 39-43. [In Russian]. Available at: https://www.iep.ru/ru/publikatcii/publication/7711.html 
[accessed on 23 May 2019].

Song, S. and Bickel, P. J. (2011). Large Vector Auto Regressions. arXiv preprint arXiv:1106.3915. Available at: https://arxiv.org/pdf/1106.3915.pdf [accessed on 23 May 2019]

Styrin, K. and Potapova, V. (2009). RenCap-NES Leading GDP Indicator Forecasts Better and Earlier. Available at: https://old.nes.ru/dataupload/files/projects/indicator/ RenCap-NES\%20Leading\%20GDP\%20Indicator\%2010\%20Dec.pdf [accessed on 23 May 2019].

Tibshirani, R. (1996). Regression Shrinkage and Selection via the LASSO. Journal of the Royal Statistical Society. Series B (Methodological), 58(1), pp. 267-288.

Turuntseva, M. (2011). Forecasting in Russia: An Overview of the Basic Models. Economic Policy, 1, pp. 193-202. [In Russian]

Turuntseva, M., Astafieva, E., Baeva, M., Bozhechkova, A., Buzaev, A., Kiblitskaya, T., Ponomarev, Yu. and Skrobotov, A. (2018). Model Calculations of Short-Term Forecasts of Social and Economic Indices of the Russian Federation. Gaidar Institute Newsletter.ru, 9 (128), pp. 3-31. [In Russian]. Available at: https://www.iep.ru/files/ Nauchniy_vestnik.ru/9-2018/3-31.pdf [accessed on 23 May 2019].

Uzyakov, M., Brusentseva, A., Gotvan, O., Gusev, M., Kaminova, S., Mironova, E., Savchishina, K., Uzyakov, R. and Shirov, A. (2009). Forecasting of Russian Macroeconomic Indicators for 2009-2012. Problemy Prognozirovaniya, 4, pp. 3-25. [In Russian].

Villani, M. (2009) Steady-State Priors for Vector Autoregressions. Journal of Applied Econometrics, 24(4), pp. 630-650.

Wilcoxon, F. (1945). Individual Comparisons by Ranking Methods. Biometrics Bulletin, 1(6), pp. 80-83.

World Bank (2018). The Russian Economy: Preserving Stability, Doubling Growth, Halving Poverty - How? Russia Economic Report, N 40. Available at: http://www.worldbank. org/en/country/russia/publication/rer [accessed on 23 May 2019]. 


\section{APPENDIX}

Table A1. Sparse pattern of the VAR-LASSO model

with a common long-run growth rate and a structural break

\begin{tabular}{|c|c|c|c|c|c|c|}
\hline \multirow{2}{*}{$\begin{array}{l}\text { Coefficien } \\
\text { testimates }\end{array}$} & \multicolumn{6}{|c|}{ Equation } \\
\hline & gdp & cons & inv & ex & im & reer \\
\hline $\operatorname{gdp}(-1)$ & 0.1469 & 0.01 & 0.0672 & 0 & 1.1875 & 0 \\
\hline cons $(-1)$ & 0 & 0.0859 & 0.4982 & 0 & 0 & 0 \\
\hline $\operatorname{inv}(-1)$ & 0.0368 & 0.016 & 0.0571 & 0 & 0.0292 & 0 \\
\hline $\operatorname{ex}(-1)$ & 0.0206 & 0.1008 & 0 & 0 & 0.1441 & 0.5026 \\
\hline $\operatorname{im}(-1)$ & 0.0063 & 0.0067 & 0.0468 & 0 & 0.0455 & 0 \\
\hline reer(-1) & 0 & 0.0934 & 0 & 0.1207 & 0.2593 & 0 \\
\hline $\operatorname{gdp}(-2)$ & 0 & 0.1361 & 0 & 0.2683 & 0 & 0 \\
\hline cons $(-2)$ & 0 & 0 & 0 & 0 & 0 & 0 \\
\hline $\operatorname{inv}(-2)$ & 0 & 0.0081 & 0 & 0 & 0 & 0 \\
\hline $\operatorname{ex}(-2)$ & 0 & 0 & 0 & 0 & 0 & 0 \\
\hline $\operatorname{im}(-2)$ & 0 & 0.0665 & 0 & 0 & 0 & 0 \\
\hline reer $(-2)$ & 0 & 0 & 0 & 0 & 0 & 0 \\
\hline $\operatorname{gdp}(-3)$ & 0 & 0 & 0 & 0 & 0 & 0 \\
\hline cons $(-3)$ & 0 & 0 & 0 & 0 & 0 & 0 \\
\hline $\operatorname{inv}(-3)$ & 0 & 0 & 0 & 0.044 & 0 & 0 \\
\hline $\operatorname{ex}(-3)$ & 0 & 0 & 0 & 0 & 0 & 0 \\
\hline $\operatorname{im}(-3)$ & 0 & 0 & 0 & 0 & 0 & 0 \\
\hline reer(-3) & 0 & 0 & 0 & 0 & 0 & 0 \\
\hline $\operatorname{gdp}(-4)$ & 0 & 0 & 0 & 0 & 0 & 0 \\
\hline cons $(-4)$ & 0 & 0 & 0 & 0 & 0 & 0 \\
\hline $\operatorname{inv}(-4)$ & 0 & 0 & 0 & 0.0377 & 0 & 0 \\
\hline $\operatorname{ex}(-4)$ & 0 & 0 & 0 & 0 & 0 & 0 \\
\hline $\operatorname{im}(-4)$ & 0 & 0 & 0 & 0 & 0 & 0.0645 \\
\hline reer(-4) & 0 & 0 & 0 & 0 & 0 & 0.1543 \\
\hline poil(0) & 0.0389 & 0.0383 & 0.0657 & 0.0687 & 0.183 & 0.1361 \\
\hline poil(-1) & 0.0275 & 0.0133 & 0.0444 & 0 & 0.0517 & 0 \\
\hline poil(-2) & 0 & 0.0104 & 0 & 0.0017 & 0 & 0 \\
\hline poil(-3) & 0 & 0 & 0 & 0.0207 & 0 & 0 \\
\hline poil(-4) & 0 & 0 & 0 & 0 & 0 & 0 \\
\hline
\end{tabular}

Table A2. VAR-LASSO forecasts for the MED baseline scenario 


\begin{tabular}{|c|c|c|c|c|c|c|c|}
\hline & GDP & Consumption & Investment & Exports & Imports & $\begin{array}{c}\text { Real } \\
\text { exchange } \\
\text { rate }\end{array}$ & $\begin{array}{l}\text { Oil price in US } \\
\text { dollars }\end{array}$ \\
\hline 2019 & $0.08 \%$ & $1.06 \%$ & $-4.61 \%$ & $-0.07 \%$ & $-3.73 \%$ & $-4.34 \%$ & 63.4 \\
\hline 2020 & $1.01 \%$ & $0.06 \%$ & $-0.27 \%$ & $-0.12 \%$ & $-2.07 \%$ & $-2.81 \%$ & 59.7 \\
\hline 2021 & $1.32 \%$ & $0.79 \%$ & $0.57 \%$ & $0.84 \%$ & $-0.38 \%$ & $-1.58 \%$ & 57.9 \\
\hline 2022 & $1.42 \%$ & $1.12 \%$ & $0.95 \%$ & $1.14 \%$ & $0.24 \%$ & $-1.03 \%$ & 56.4 \\
\hline 2023 & $1.46 \%$ & $1.23 \%$ & $1.08 \%$ & $1.24 \%$ & $0.48 \%$ & $-0.80 \%$ & 55.1 \\
\hline 2024 & $1.42 \%$ & $1.21 \%$ & $1.02 \%$ & $1.22 \%$ & $0.34 \%$ & $-0.83 \%$ & 53.5 \\
\hline
\end{tabular}

Table A3. VAR-LASSO forecasts for the MED conservative scenario

\begin{tabular}{|c|c|c|c|c|c|c|c|}
\hline & GDP & Consumption & Investment & Exports & Imports & $\begin{array}{c}\text { Real } \\
\text { exchange } \\
\text { rate }\end{array}$ & $\begin{array}{c}\text { Oil price } \\
\text { in US dollars }\end{array}$ \\
\hline 2019 & $-0.83 \%$ & $-0.09 \%$ & $-6.33 \%$ & $-1.27 \%$ & $-7.65 \%$ & $-6.31 \%$ & 56 \\
\hline 2020 & $-0.83 \%$ & $-2.77 \%$ & $-4.34 \%$ & $-2.94 \%$ & $-10.24 \%$ & $-7.33 \%$ & 42.5 \\
\hline 2021 & $1.21 \%$ & $-0.41 \%$ & $-0.56 \%$ & $-0.12 \%$ & $-1.55 \%$ & $-3.07 \%$ & 43.3 \\
\hline 2022 & $1.83 \%$ & $1.62 \%$ & $1.76 \%$ & $1.61 \%$ & $1.94 \%$ & $-0.56 \%$ & 44.2 \\
\hline 2023 & $1.86 \%$ & $1.94 \%$ & $2.07 \%$ & $1.94 \%$ & $2.44 \%$ & $0.28 \%$ & 45 \\
\hline 2024 & $1.88 \%$ & $2.02 \%$ & $2.15 \%$ & $2.01 \%$ & $2.61 \%$ & $0.51 \%$ & 45.9 \\
\hline
\end{tabular}

Table A4. VAR-LASSO forecasts for the IMF scenario

\begin{tabular}{c|c|c|c|c|c|c|c} 
& GDP & Consumption & Investment & Exports & Imports & $\begin{array}{c}\text { Real } \\
\text { exchange } \\
\text { rate }\end{array}$ & $\begin{array}{c}\text { Oil price } \\
\text { in US dollars }\end{array}$ \\
\hline 2019 & $0.68 \%$ & $1.83 \%$ & $-3.45 \%$ & $0.74 \%$ & $-1.05 \%$ & $-3.01 \%$ & 68.8 \\
\hline 2020 & $1.63 \%$ & $1.20 \%$ & $1.27 \%$ & $0.96 \%$ & $0.90 \%$ & $-1.09 \%$ & 68.8 \\
\hline 2021 & $1.68 \%$ & $1.60 \%$ & $1.60 \%$ & $1.61 \%$ & $1.54 \%$ & $-0.28 \%$ & 68.8 \\
\hline 2022 & $1.69 \%$ & $1.67 \%$ & $1.67 \%$ & $1.68 \%$ & $1.66 \%$ & $-0.07 \%$ & 68.8 \\
\hline 2023 & $1.69 \%$ & $1.69 \%$ & $1.69 \%$ & $1.69 \%$ & $1.69 \%$ & $-0.02 \%$ & 68.8 \\
\hline 2024 & $1.69 \%$ & $1.69 \%$ & $1.69 \%$ & $1.69 \%$ & $1.69 \%$ & $0.00 \%$ & 68.8 \\
\hline
\end{tabular}

Table A4. VAR-LASSO forecasts for the WB scenario

\begin{tabular}{|c|c|c|c|c|c|c|c|}
\hline & GDP & Consumption & Investment & Exports & Imports & $\begin{array}{c}\text { Real } \\
\text { exchange } \\
\text { rate }\end{array}$ & $\begin{array}{c}\text { Oil price } \\
\text { in US dollars }\end{array}$ \\
\hline 2019 & $0.91 \%$ & $2.13 \%$ & $-3.00 \%$ & $1.05 \%$ & $0.00 \%$ & $-2.50 \%$ & 71 \\
\hline 2020 & $1.69 \%$ & $1.42 \%$ & $1.52 \%$ & $1.15 \%$ & $1.28 \%$ & $-0.80 \%$ & 71 \\
\hline 2021 & $1.69 \%$ & $1.64 \%$ & $1.64 \%$ & $1.65 \%$ & $1.60 \%$ & $-0.18 \%$ & 71 \\
\hline 2022 & $1.69 \%$ & $1.68 \%$ & $1.68 \%$ & $1.68 \%$ & $1.67 \%$ & $-0.04 \%$ & 71 \\
\hline 2023 & $1.69 \%$ & $1.69 \%$ & $1.69 \%$ & $1.69 \%$ & $1.69 \%$ & $-0.01 \%$ & 71 \\
\hline 2024 & $1.69 \%$ & $1.69 \%$ & $1.69 \%$ & $1.69 \%$ & $1.69 \%$ & $0.00 \%$ & 71 \\
\hline
\end{tabular}

